\title{
Characterization of consensus operator site for Streptococcus pneumoniae copper repressor, CopY
}

Henrik O’Brien ${ }^{1 *}$, Joseph W. Alvin ${ }^{1 *}$, Sanjay V. Menghani ${ }^{1}$, Koenraad Van Doorslaer ${ }^{1,2,3}$, and Michael D. L. Johnson ${ }^{1,2,4}$

${ }^{1}$ Department of Immunobiology

University of Arizona

Tucson, AZ

${ }^{2} \mathrm{BIO5}$ Institute

11 University of Arizona

12 Tucson, AZ

$13{ }^{3}$ School of Animal and Comparative Biomedical Sciences, Cancer Biology Graduate

14 Interdisciplinary Program, Genetics Graduate Interdisciplinary Program, and University of

15 Arizona Cancer Center

16 University of Arizona

17 Tucson, AZ

$18{ }^{4}$ Valley Fever Center for Excellence

19 University of Arizona

20 Tucson, $A Z$

21

22

23

* These authors contributed equally to this work

Michael D. L. Johnson

University of Arizona

1656 E. Mabel St. / P.O. Box 245221 / MRB 221 (office)

Tucson, AZ 85724

Tel: 520-626-3779 / Fax: 520-626-2100 


\section{ABSTRACT}

30 Copper is broadly toxic to bacteria. As such, bacteria have evolved specialized copper export

31 systems (cop operons) often consisting of a DNA-binding/copper-responsive regulator (which

32 can be a repressor or activator), a copper chaperone, and a copper exporter. For those bacteria

33 using DNA-binding copper repressors, few studies have examined the regulation of this operon

34 regarding the operator DNA sequence needed for repression. In Streptococcus pneumoniae

35 (the pneumococcus), CopY is the copper repressor for the cop operon. Previously, these

36 homologs have been characterized to bind a 10-base consensus sequence T/GACAnnTGTA.

37 Here, we bioinformatically and empirically characterize these operator sites across species

38 using S. pneumoniae CopY as a guide for binding. By examining the 21-base repeat operators

39 for the pneumococcal cop operon and comparing binding of recombinant CopY to this, and the

40 operator sites found in Enterococcus hirae, we show using biolayer interferometry that the

41 T/GACAnnTGTA sequence is essential to binding, but it is not sufficient. We determine a more

42 comprehensive S. pneumoniae CopY operator sequence to be RnYKACAAATGTARnY (where

43 " $R$ " is purine, " $Y$ " is pyrimidine, and " $K$ " is either G or T) binding with an affinity of $28 \mathrm{nM}$. We

44 further propose that the cop operon operator consensus site of pneumococcal homologs be

45 RnYKACAnnYGTARnY. This study illustrates the necessity to explore bacterial operator sites

46 further to better understand bacterial gene regulation. 


\section{INTRODUCTION}

Metals are essential nutrients to all living organisms. They are used as co-factors and

50 structural components in a vast number of cellular processes. Iron, and manganese are

51 examples of first-row divalent transition metals used by living organisms. Properties such as

52 ability to form stable complexes play a vital role as to how each metal is used in the organism.

53 The stability of biological complexes is characterized by the Irving-Williams series $(\mathrm{Mn}<\mathrm{Fe}<$

$54 \mathrm{Co}<\mathrm{Ni}<\mathrm{Cu}>\mathrm{Zn}$ ) (1). In general, more stable complexes correlate to a metal's toxicity, as

55 native metals for an active site can be displaced by another metal ion further along in the

56 observed series. This process is known as mismetallation and is primarily due to the promiscuity

57 of different metal binding motifs (2). Higher order organisms have evolved ways to tightly

58 regulate and use these metals, thus reducing some promiscuity in displacement. For most

59 prokaryotes, however, metals like copper, nickel, and cobalt are broadly toxic. Within

mammalian systems, copper is the most utilized and biologically relevant of these three metals

61 (3-7). As such, in a process called nutritional immunity, mammalian hosts have evolved

62 strategies to both sequester the universally necessary metals from bacteria (e.g., Fe, Mn, Ca)

63 and bombard them with toxic metals such as copper and zinc (8, 9). Although Fenton chemistry

64 mediated toxicity can occur in bacteria, the majority of copper-specific toxicity has been

65 observed via mismetallation with iron-sulfur clusters, nucleotide synthesis, and glutamate

66 synthesis (10-14).

Bacteria have evolved specialized import and export systems to acquire necessary

68 metals and to adapt to metal toxicity. The presence of these import and export systems within

69 the bacteria is usually based on need for the metal. Iron, for instance, is an essential metal for

70 Streptococcus pneumoniae (the pneumococcus), a Gram-positive pathogen that causes

71 pneumonia, meningitis, otitis media, and septicemia. In S. pneumoniae, iron has four known

72 import systems, Pia, Piu, Pit, and the hemin binding system encoded by SPD_1590 (D39

73 strain), but no known export systems $(15,16)$. Whereas calcium, zinc, and manganese all have 
74 export and import systems, the pneumococcus has no known import system for copper but

75 contains a dedicated copper export system encoded by the cop operon (16-21). In general,

76 Gram-positive, and some Gram-negative bacterial copper export systems consist of a cop

77 operon regulator, a copper chaperone, and one or two copper exporters (17, 22-28). Mutations

78 in the copper export protein in cop operons result in decreased bacterial virulence, highlighting

79 the importance of nutritional immunity and copper toxicity in $S$. pneumoniae $(17,27,29,30)$.

The cop operon regulators function as either activators or repressors. Although there are

81 cop operon activators and repressors in structurally distinct groups, they all serve to protect the

82 bacteria against copper stress by sensing copper and facilitating its export. Activators are

83 proteins that sense copper and activate gene expression in response, such as CueR in

84 Escherichia coli (31). Occurring in species such as Lactococcus lactis and S. pneumoniae

$85(\mathrm{CopR} / \mathrm{Y})$, and in Listeria monocytogenes and Mycobacterium tuberculosis (CsoR), the cop operon repressors remain bound to DNA in environments lacking copper stress to block

87 transcription, and release DNA upon binding copper (16, 24, 27, 32-34).

The CopR/Y family of cop operon repressors have consensus copper binding protein motifs, Cys-X-Cys. Each $\mathrm{CxC}$ motif (or $\mathrm{CxxC}$ ) can bind in a 1:1 ratio with copper. These motifs can also bind zinc with a stoichiometry of two $\mathrm{CxC}$ motifs needed to bind one zinc (33). Copper

91 binding causes a conformational change in the copper repressor leading to the DNA-binding

92 release of what was thought to be the full cop operon operator, T/GACAnnTGTA (where $n$

93 represents any nucleotide), while zinc binding leads to tighter cop operon operator binding (32,

94 33). However, the atomic and protein structural detail of how binding metal directly leads to the 95 conformational changes associated with DNA binding is currently unknown.

96 Multiple studies regarding the cop operon have been performed in S. pneumoniae (11,

$9717,27,32,33,35,36)$. The pneumococcal cop operon contains, cop $Y$ as the repressor, cupA

98 as a membrane-associated copper chaperone, and copA as the copper-specific exporter (16,

99 27, 32). Although the affinities of CopY/R family repressors for copper are generally high, the 
100 pneumococcal chaperone CupA is able to chelate copper from CopY, reduce it from $\mathrm{Cu}^{2+}$ to

$101 \mathrm{Cu}^{1+}$, and transport copper to CopA for export $(32,35-37)$. CupA copper chelation allows for the

102 recycling of CopY and its apo- or zinc-bound form to return to the cop operator to repress the

103 operon. Pneumococcal CopY is homologous to several known antibiotic resistance repressors

104 including Blal, a Staphylococcus aureus Mecl homolog that represses the gene for a $\beta$ -

105 lactamase (32, 33, 38). Like CopY, Blal and Mecl interact with a known operator sequence,

106 TACA/TGTA, form a homodimer, and are mostly helical in secondary structure $(32,38)$.

107 However, unlike CopY, Blal does not have a known metal binding site and is regulated by

108 proteases (39).

109 Here, we present bioinformatic data on the homology of cop operon operators and DNA-

110 binding assays using recombinant pneumococcal CopY to characterize binding to the cop

111 operon operator. We determined the consensus pneumococcal operator site, that

112 pneumococcal CopY can bind to both operators relatively equally and independently, and that

113 species with CopY homologs contain either one or two consensus operators but that species

114 with two sites do not always have identical repeats. 
MATERIALS AND METHODS

\section{Aligning and Comparing CopY homologs and promoter sequences}

117 The BLAST sequence alignment algorithm was used to align both E. hirae and TIGR4 S.

118 pneumoniae cop operon promoter regions, the 21-base repeats upstream of the TIGR4

119 pneumococcal cop operon, and the promoter regions of pneumococcal species (40). A set of

120 custom Python scripts (available from https://github.com/Van-Doorslaer/Alvin_et_al_2018) were

121 used to assign identified copY homologs to bacterial genomes and extract the suspected

122 regulatory region from individual species (100 bases upstream of the start codon). Importantly,

123 in many cases, the initial blast search identified CopY homologs which matched multiple

124 species' isolates/strains. In this case, the identified proteins were again compared to the NCBI

125 database, and the homolog with the lowest E-value was retained. The identified CopY homolog

126 was not necessarily identical to the original query. If this approach was unsuccessful, the

127 homolog was excluded from further analysis.

Protein purification

130 CopY protein was purified as in Neubert et. al.(32), with modifications. The pMCSG7 vector

131 includes an N-terminal 6x-His tag linked to CopY via a Tobacco Etch Virus protease (TEV)

132 cleavage site(41). Unless specified, all steps were performed on ice or at $4{ }^{\circ} \mathrm{C}$. After initial

133 purification using immobilized metal-affinity chromatography (IMAC) (HisTrap FF, GE

134 Healthcare), the crude CopY sample was incubated at $23^{\circ} \mathrm{C}$ with a $100: 1$ mass ratio of

135 recombinant TEV. The cleaved CopY was purified with subtractive IMAC (our TEV protease

136 contains a C-terminal His tag). The flow-through was further purified by size-exclusion

137 chromatography (SEC) (Superdex 200, GE Healthcare) using a buffer of $20 \mathrm{mM}$ Tris pH 8, 200

$138 \mathrm{mM} \mathrm{NaCl}, 1 \mathrm{mM}$ tris(2-carboxyethyl)phosphine (TCEP). Peaks containing pure CopY (as

139 determined by SDS-PAGE) were pooled and concentration was determined by absorbance at 
$280 \mathrm{~nm}$. Samples were used immediately or protected with $35-50 \%$ glycerol and aliquoted into

141 thin-walled PCR tubes containing $30 \mu \mathrm{L}$. These aliquots were then flash-frozen using liquid $\mathrm{N}_{2}$.

\section{Electromobility Shift Assay (EMSA)}

144 Primers for binding, 5'-

145 TAATTGACAAATGTAGATTTTAAGAGTATACTGATGAGTGTAATTGACAAATGTAGATTTT -3’ 146 and $5^{\prime}-$

147 AAAATCTACATTTGTCAATTACACTCATCAGTATACTCTTAAAATCTACATTTGTCAATTA -

1483 , were annealed by heating a 1:1 molar equivalent of each strand to $95^{\circ} \mathrm{C}$, then reducing the

149 temperature by $\sim 1^{\circ} \mathrm{C} /$ minute to $22^{\circ} \mathrm{C}$. EMSA buffer was Tris-borate (TB) electrophoresis buffer

150 (EDTA was left out to diminish metal chelation). Samples were incubated at $4^{\circ} \mathrm{C}$ for 5 minutes,

151 loaded onto a 5\% polyacrylamideTBE gel (Bio-Rad) that had been pre-run for 15 minutes in TB

152 Buffer. Samples were electrophoresed at $40 \mathrm{~V}$ for 120 minutes. The polyacrylamide gel was

153 stained with $0.02 \%$ ethidium bromide (Amresco) and imaged a Gel Doc XR+ System (Bio-Rad).

Octet DNA/protein binding

156 Double stranded DNA fragments were prepared by incubating a 5' biotinylated ssDNA with a

157 complementary strand at $95^{\circ} \mathrm{C}$ for 5-10 minutes then left on benchtop to cool to room

158 temperature (Table S1). The dissociation constant for CopY with various DNA fragments was

159 determined using an Octet Red384 (Pall ForteBio). Streptavidin biosensors (Pall ForteBio) were

160 hydrated at $26^{\circ} \mathrm{C}$ using the Sidekick shaker accessory for $10 \mathrm{~min}$ at $1000 \mathrm{rpm}$. Biotinylated

161 DNA fragments were diluted to 250 or $50 \mathrm{nM}$, depending on the levels of biosensor loading, in

162 the assay buffer (50 mM Tris $\mathrm{pH} 7.4,150 \mathrm{mM} \mathrm{NaCl}, 4 \%$ glycerol, $1 \mathrm{mM}$ TCEP, $1 \mathrm{mM} \mathrm{NaN}$,

$1630.1 \%$ Bovine Serum Albumin (BSA). During initial optimization, we observed significant non-

164 specific binding of CopY to the biosensors in the absence of BSA. The inclusion of $0.1 \%$ BSA

165 eliminated signals of nonspecific CopY binding at the highest concentrations used in the assay 
$166(3 \mu \mathrm{M})$. Hydrated sensors were incubated in the assay buffer to acquire a primary baseline. The

167 sensors were then loaded with biotinylated dsDNA, followed by a secondary baseline

168 measurement using wells with buffer solution. DNA-loaded biosensors were then moved to

169 wells containing varying CopY concentrations to measure association then placed back into

170 assay buffer for dissociation recordings. All experiments were maintained at $26^{\circ} \mathrm{C}$ with shaking

171 at $1000 \mathrm{rpm}$. The optimized protocol was as follows: $1^{\circ}$ baseline $60 \mathrm{~s}$, DNA loading $300 \mathrm{~s}, 2^{\circ}$

172 baseline $180 \mathrm{~s}$, association $180 \mathrm{~s}$, and dissociation $270 \mathrm{~s}$. The methods were optimized to

173 minimize sharp association peaks and minimize recording at equilibria.

174 Analysis was performed using the Octet software. We applied a 1:1 (for dsDNA including one

175 site) binding model using a global fit to biosensor replicates at each concentration of CopY.

176 During pre-processing, an average of the $2^{\circ}$ baseline across the various biosensors was

177 applied, as well as Savitzkty-Golay filtering to reduce noise. The data were inter-step corrected

178 using an alignment to the dissociation step. Data were modeled using combined fits of $k_{a}$ and $k_{d}$

179 values across independent replicates. Final estimates for $K_{d}$ and related statistics were taken

180 from the kinetic analysis.

181 Rate constants for each sample were determined using the Octet analysis software as follows.

182 For all 1:1 stoichiometric modelling, complex formation was evaluated as pseudo-first-order

183 kinetics. The observed rate constant $\left(\mathrm{k}_{\mathrm{obs}}\right)$ was calculated according to the equation $\mathrm{Y}=\mathrm{Y}_{0}+$

$184 \mathrm{~A}\left(1-\mathrm{e}^{-\mathrm{k}_{o b s} \times \mathrm{t}}\right)$. Where $\mathrm{Y}_{0}=$ initial binding, $\mathrm{Y}=$ level of binding, $\mathrm{t}=$ time, and $\mathrm{A}=$ asymptote value

185 at max response. Dissociation rate $\left(\mathrm{k}_{d}\right)$ was calculated according to the equation $\mathrm{Y}=\mathrm{Y}_{0}+$

$186 \mathrm{Ae}^{-\mathrm{k}_{\mathrm{d}} \times \mathrm{t}}$. The calculated $\mathrm{k}_{o b s}$ and $\mathrm{k}_{d}$ values were then used to determine $\mathrm{k}_{\mathrm{a}}$ using the equation

$187 \mathrm{k}_{a}=\frac{k_{o b s}-k_{d}}{\left[{ }^{C o p Y}\right]}$. Finally, the dissociation constant $\left(\mathrm{K}_{\mathrm{d}}\right)$ was determined by the identity $\mathrm{K}_{D}=\frac{k_{d}}{k_{a}}$. 


\section{RESULTS}

\section{cop operator homology and frequency}

Early DNA-binding studies were carried out using a CopY homolog from Enterococcus

191 hirae on the interactions with the cop operon operator $(22,42,43)$. We recently observed that

192 there are two large repeats upstream of the pneumococcal cop operon that include a 10-base

193 sequence important for CopY binding. These motifs differed slightly from those observed in $E$.

194 hirae (Figure 1A). Although the amino acid sequence of the E. hirae copper repressor and the

195 upstream binding repeats are highly similar to $S$. pneumoniae $(32,33)$, and contain the 10 -base

196 sequence, E. hirae operators upon initial observation lacked the extended regions flanking this

197 sequence in pneumococcus (Figure 1B) (22). A BLAST search revealed that the 61-base

198 stretch of DNA upstream of the pneumococcal cop operon that includes the two extended 21-

199 base repeats is highly conserved in all pneumococcal species (40). Related searches identified

200 that some bacterial species only contain a single operator upstream of their respective cop

201 operons. DNA-binding studies for the cop operon operator and CopY/R (including homologs)

202 have not been performed for two identical operators to determine in vitro affinity values with the

203 closest being Portmann et. al (42).

We performed BLASTp searches for S. pneumoniae TIGR4 CopY homologs first

205 excluding, then specific to the Streptococcus genus (40). Using a max target sequence number

206 of 1000 for each search, then combining both lists, we found 335 different entries (Table S2).

207 From this list, we extracted protein sequences from the unique NCBI accession numbers (many

$208 \mathrm{NCBI}$ accession numbers represented several/identical species) and then, the 100 bases

209 upstream of the respective copper repressor start codon (Table S3, S4). Many of the 141

210 unique protein sequences belonged to species in the Streptococcus and Lactobacillus genera

211 (Table S3). This table also included species such as the yogurt probiotic Lactobacillus

212 acidophilus and Mycobacteroides abscessus, an emerging multidrug resistant pathogen that

213 causes lung, skin, and soft tissue infections) (44). 
We used programs within the MEME suite to identify DNA repeats within a 100-base upstream fragment, which would correspond to promoter and suspected operator-containing

216 regions from 88 unique sequences $(45,46)$. As predicted by known CopY/R operators, the

217 dominant 21-base sequence contained T/GACAnnTGTA (hereafter KACAnnTGTA) (Figure 2A)

218 (47). Of these 88 sequences, 67 had two CopY/R cop operon operators such as TIGR4,

219 Streptococcus pyogenes, E. hirae, and Enterococcus faecium, 14 had one cop operon operator

220 such as Enterococcus faecalis, and 7 had none with no other consensus sequence found

221 (Figures 2B-D, Tables S5-S7). Increasing the bases upstream maximum to 500 did not yield

222 additional sequences (data not shown). For the genomes with two cop operators, we found that

223 most of the operators were between 24 and 39 bases from each other with the mode being 26

224 bases (Figure S1). Of the species that had a single cop operon operator, the consensus

225 sequences were more variable KACAnnYGTA (Table S6). Of these 14 sequences, 7 were on

226 the positive strand (but six were palindromic) and 7 non-palindromic sequences were on the

227 negative strand (Table S6).

228 With the sequences that had no consensus cop operon operators for CopY/R, six were

229 in the Lactobacillus genus and one in the Macrococcus genus (Table S7). For these seven

230 strains that had no consensus cop operon operator, MEME suite did not identify a consensus

231 sequences consistent across those seven strains. A BLAST search also found no significant

232 similarity between the DNA fragments. Additionally, a separate, in silico search of these

233 operators did not yield a consensus sequence consistent between the strains.

\section{CopY binds to both cop operators}

Previous studies showed that CopY specifically bound to the cop operon operator in a

237 sequence and metal specific manner as disrupting the operator bases or adding copper

238 disrupted CopY binding, while adding manganese or iron had no detectable effect (32). These

239 studies were done with only one full operator intact $(32,33)$. Thus, using an electric mobility shift 
assay (EMSA), we qualitatively tested CopY binding to DNA to the two-operator 61-base dsDNA

241 fragment. As evaluated by EMSA, CopY bound in a dose-dependent manner (Figure 3).

242 Consistent with having two different cop operon operators, titrating CopY with the two-operator

243 DNA showed two distinct shifts via EMSA (Figure 3).

244 To quantitatively determine affinities to one or both operators, we used biotinylated DNA

245 oligos and recombinant CopY protein using biolayer interferometry (BLI). All BLI binding

246 experiments are done with dsDNA unless otherwise noted. These experiments demonstrated

247 that the two-site DNA had a similar affinity $\left(\mathrm{K}_{d}=28.1 \mathrm{nM}\right)$ to the proximal DNA (DNA that has

248 the distal site scrambled) $\left(K_{d}=25.5 \mathrm{nM}\right)($ Table 1, Figure $4 \mathrm{~A}, \mathrm{~B})$. The distal site DNA (DNA that

249 has the proximal site scrambled) had a slightly lower affinity ( $\left.K_{d}=55.2 n M\right)$ (Table 1, Figure 4B).

250 However, a 2-fold change in affinity is within the error of the machine, thus indicating that all

251 sites bind similarly and independently of each other. Further, this 2-fold difference could be

252 attributed to the biotin tag on the 5' end of the DNA slightly interfering with binding. Given the

253 comparable affinities, it is likely that binding at each operator is non-cooperative-i.e., CopY

254 dimers do not appear to have quaternary. As expected, CopY bound DNA constructs containing

255 intact 21-base repeat containing cop operon operators with significantly higher affinities

256 compared to a scrambled DNA negative control (scram) or a ssDNA containing the two-site

257 operator which both exhibited extremely weak binding (Figure 4D, data not shown). Taken

258 together, CopY binds both 21-base repeats containing the operator sites independently of each

259 other with nanomolar affinity.

261 Determining a consensus CopY-family operator

262 With a reported consensus binding sequence of KACAnnTGTA on the leading strand,

263 we hypothesized that CopY may also bind other similar sequences as previously seen in

264 Lactococcus lactis (48). Allowing for one base variation from the reported binding sequence, we

265 found matches upstream of genes upregulated under copper stress and hypothesized that they 
may also be regulated by CopY $(11,49)$. Seven potential binding sites were assessed using BLI. To our surprise, CopY did not bind to any of the fragments (Figure 5, Table 2, S2). literature may be necessary, but not sufficient for CopY binding. For this experiment, we took a scrambled negative control DNA and added back only the known 10-base consensus sequence

271 to where it exists in the second operator site. We found that CopY did not bind this fragment

272 above the level of our negative controls (Figure 6A). Taken together, these and with prior data,

273 we have concluded that the reported consensus binding operator is necessary, but not sufficient

274 for binding (22).

We next wanted to establish which bases outside of the previously reported 10-base

276 consensus sequence were necessary for CopY binding. Using the proximal 21-base motif as a

277 model, two fragments were generated: one containing the five bases upstream and another

278 containing six bases downstream of the sequence. Neither of these fragments showed notable

279 binding above that of the scrambled constructs suggesting that there are important bases on

280 both sides of the 10-base sequence (Figure 6B). Next, two new constructs were tested to

281 assess binding; one had the 10-base consensus sequence + two bases upstream and

282 downstream for a total of 14 bases out of the full 21-base motif, and one had the 10-base

283 consensus site + three bases to each side of the consensus was created for a total length of 16

284 bases out of the full 21-base motif. The 14-base sequence did not display binding above that of

285 negative controls $\left(\mathrm{K}_{d}>3 \mu \mathrm{M}\right)$, but the 16-base sequence displayed binding (Figure 6C, S3,

286 Table 1). While these 16-base DNA had a 10-fold lower binding affinity than the full 21-base

287 site, these levels of binding suggest that the 16 bases make up the core operator site

288 recognized by CopY and additional bases increase affinity at the site. Extending the sequence

289 to 19 of the 21 bases led to comparable levels of binding to the full sequence (Figure 6D).

290 Taking into account 1) our results for adding three bases on each side of the 10-base

291 reported sequence in pneumococcus, 2) looking externally of the 10-base fragments in L. lactis 
292 that it was predicted the repressor would bind to (with some binding and some not binding), and

293 3) analyzing the alignment of bacterial species operator sites via Meme Suite (Figs. 1A, 2A,

294 Table S5) a clear pyrimidine-n-purine motif on each side of the 10-base sequence was revealed

295 to be RnYKACAnnTGTARnY (where "R" is purine, "Y" is pyrimidine, and "K" is either G or T)

296 (48).

The initial characterization of the cop operon operator site occurred using the E. hirae

298 genome $(22,50)$. Thus, to gather more details on the consensus pneumococcal CopY operator

299 site, and test this extended operator hypothesis, we used E. hirae DNA with the distal or

300 proximal operators intact and examined it for pneumococcal CopY binding. The E. hirae DNA

301 had several differences to test the new operator hypothesis; 1) the $E$. hirae DNA sites have a

302 "T" instead of the G found in S. pneumoniae in the initial 10 base consensus operator and this is

303 notated as "K"; 2) the middle bases of the 10-base sequence, previously notated as "n", are the

304 same in the distal site ("AA"), but "GT" in the proximal site; and 3) both had three of the four

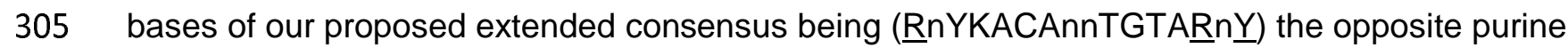

306 or pyrimidine base as compared to pneumococcus (Figure 1B). Pneumococcal CopY bound to

307 the distal site implying that the predictions of "K" in the previous 10-base consensus operator

308 and the three changed purines and pyrimidine were correct (Figure 7A). However,

309 pneumococcal CopY did not bind to the proximal site implying that the "AA" notated as "nn" in

310 the previous 10-base consensus sequence indeed needed to be "AA" (Figure 7B).

311 Lastly, we tested our hypothesis that it is a pyrimidine or purine in the given positions 1 ,

3123,14 , and 16 , and not the specific base that matters by mutating the pyrimidine $T$ at position 3

313 (ATIGACAAATGTAGAT), to $\mathrm{C}$ (pyrimidine) and to A (purine) in the 19-base DNA fragment. We

314 used the 19-base fragment versus the 16-base fragment here to better detect changes in

315 binding affinity between the samples. Of the four bases outside of the 10-base consensus

316 sequence that we made predictions for, the pyrimidine at position 3 is the only base that was the

317 same in the E. hirae DNA fragment. As expected within our model, the T to $\mathrm{C}$ mutation did not 
318 significantly alter the binding affinity as compared to the 19-base fragment, while the $\mathrm{T}$ to $\mathrm{A}$

319 mutation completely abolished binding (Figure 7C, D). Taken together, we believe the

320 pneumococcal consensus operator is RnYKACAAATGTARnY as opposed to the previously

321 reported KACAnnTGTA (Figure 8).

322 


\section{DISCUSSION}

Here, we populated a list of pneumococcal CopY homologs, assessed them for the

325 number of upstream operators, determined the affinity of pneumococcal CopY for each of its

326 two operators, and elucidated the complete sequence of the pneumococcal cop operon operator

327 (RnYKACAAATGTARnY) which is greatly expanded from the previously reported

328 KACAnnTGTA (Figure 8). As expected from the homology of the cop operon repressors, we

329 observed binding of one species' repressor to the DNA of another, but this binding was not

330 absolute as pneumococcal CopY bound to only one of the E. hirae sites.

331 Given the previous 10-base consensus sequence, it was plausible to propose that like in

332 L. lactis, there were additional binding sites that the cop repressor could bind. Furthering the

333 biological relevance of this proposition was that some sequences in S. pneumoniae

334 corresponded to putative promoter regions of genes and operons upregulated under copper

335 stress, thus implying that CopY was a master regulator of several operons under copper stress

336 (11). By showing no binding of these sequences that followed the 10-base consensus, and the

337 10-base sequence itself, we demonstrated that the 10-base sequence was not sufficient for

338 binding. This fact ultimately led us to searching for and deriving the pneumococcal consensus

339 sequence. Given this new pneumococcal consensus sequence, a new search in multiple

340 Streptococcal species for potential operators yielded no additional sites (49). However, as in the

341 L. lactis CopR binding to multiple operators in its genome, this is likely not the case with all

342 bacteria containing CopY homologs (48).

343 In generating the list of CopY/R genes and proteins, we also were able to look upstream

344 of the gene and compile what we believe to be a general consensus operator site which differs

345 slightly from the newly proposed pneumococcal version. The two changes from the

346 pneumococcal operator we propose are 1) returning to the "nn" in the middle of the previous 10-

347 base consensus sequence and 2) changing base 10 from " $T$ " to " $Y$ " based on having $T$ or $\mathrm{C}$ in

348 the meme suite alignment. These changes yield what we propose to be the new consensus cop 
operon operator "RnYKACAnnYGTARnY" (Figure 8). This new consensus operator was able to explain why CopY bound a subset of our tested sites. Furthermore, the model also explains the results presented by Magnani et. al._using the L. lactis CopR protein (Table 2) (48). As such, consensus operator sequences for various repressors should be revisited to better reveal potential binding interactions within their respective genomes. containing only one intact operator $(17,32,33)$. However, we show that Streptococcus and

356 many other genera have two binding sites upstream of the cop operon. In some cases (e.g.,

357 Streptococcus), these sites are identical, while other sites have slight sequence variation (e.g.,

358 E. hirae) (Figure 1A). Despite having two identical 21-base repeat operators, the S. pneumoniae

359 cop operon two-operator DNA does not have tighter binding to CopY as compared to the

360 proximal or distal operator. This result is contrary to what was expected as more DNA-binding

361 sites in sequence tend to increase overall protein affinity for those sites of regulation. While it is

362 clear that CopY does not need a second operator present to bind DNA, this result does not

363 necessarily rule out that cop operons with two operators is more tightly regulated than if only

364 one operator was present.

365 Regarding how stringently the cop operon is controlled, we propose that the two

366 pneumococcal operators do indeed serve to add additional restraint to cop operon transcription.

367 We hypothesize that the two pneumococcal operators do indeed serve to add additional

368 restraint to cop operon transcription. We also suggest that the distal operator prevents sigma

369 factors from binding at the copY -35 element. and the proximal operator occludes RNA

370 polymerase; establishing two layers of repression for the cop operon (51). This reasoning is also

371 consistent to the proposed hypothesis of why there are two operators in the antibiotic resistance

372 repressor Blal (52). These hypothesizes are the subject of our group's ongoing research. Still,

373 S. pneumoniae with its two CopY operators and with multiple levels of regulation comes as a

374 surprise for an operon in which A) upregulation is linked to increased pneumococcal survival in 
375 the host and B) $\Delta \operatorname{cop} Y$ mutant has increased virulence in mice $(27,53)$. We anticipate that

376 further study of these systems in S. pneumoniae will yield clues as to the competitive

377 advantages or selective pressures of the cop operon in its pathological context.

378

379

380 CONFLICTS OF INTEREST

381 There are no conflicts to declare.

382

\section{ACKNOWLEDGEMENTS}

384 The authors would like to thank Rachel Wong, the University of Arizona Functional Genomics

385 Core Facility, and Richard Yip for assistance and support using the Octet Red384. This work

386 was funded by an NIGMS grant 1R35128653 (MDLJ). 
FIGURE LEGENDS

Table 1. Data and model statistics from Octet kinetic experiments. Listed dsDNA fragments and conditions were used with streptavidin probes and tested with recombinant CopY protein.

Table 2. Outcomes of CopR or CopY binding to potential operator sites from L. lactis (Magnani et al., 2008) or S. pneumoniae respectively. Red bases indicate bases varying from the reported 10-base consensus sequence.

Figure 1. TIGR4 has two 21-base repeats containing the consensus CopY operators. A. Aligned 21-base sequences for the two CopY operators. B. TIGR4 SP_0727 promoter region sequence (containing both 21-base repeats) aligned with the E. hirae ATCC strain 9790. Identical bases are underlined for the respective regions containing the operator.

Figure 2. CopY cop operon operator consensus sequences in the genomic DNA. A. Top consensus DNA sequence contained within the 87 unique upstream 100 bases sequences to the respective CopY organism as detected by MEME suite. The literature-based operator from Tables S5.

Figure 3. CopY binds to both cop operon operators. EMSA with CopY and two-site

409 (operator) DNA. In seven of eight wells, a final concentration of 50 nM DNA was used with

410 protein concentrations titrated by 2.5 -fold dilutions from $640 \mathrm{nM}$ to $41 \mathrm{nM}$. A final concentration

411 of $640 \mathrm{nM}$ CopY was used in a protein-without-DNA control with each replicate. 
Figure 4. Affinity measurements for CopY and the cop operon operators. DNA fragments were loaded onto a biosensor and tested with $1000 \mathrm{nM}$ (blue), $500 \mathrm{nM}$ (red), $250 \mathrm{nM}$ (light blue), $125 \mathrm{nM}$ (green), $62.5 \mathrm{nM}$ (orange), $15.6 \mathrm{nM}$ (purple) CopY (A-D).

416 Proximal site D. Scram. For each figure, data is representative of at least three experimental 417 replicates.

Figure 5. Prediction of CopY binding based on 10-base sequence overestimates binding sites. CopY at $3 \mu \mathrm{M}$ was used to assess binding to DNA fragments containing potential CopY operators upstream of the respective genes $S P \_00901$ (red), SP_00902 (light blue), SP_0045

422 (green), $S P_{-} 0530$ (orange), $S P_{-} 1433$ (purple), with controls for two-site (blue), scram (gray), no

423 DNA (red-orange). For each figure, data is representative of three experimental replicates.

Figure 6. The minimum operator for sufficient CopY binding is 16 bases in length. A.

427 Binding of the 10-base fragment compared to positive and negative controls. Two-site (blue),

428 Two-site no protein (red), 10-base (green), scram (orange), no DNA (purple). B. DNA fragments 429 containing either the upstream (5 bases) or downstream (6 bases) of the 10-base sequence 430 within 21-base repeat compared to positive and negative controls. Proximal site (blue), five 431 bases upstream (red), six bases downstream (light blue), 10-base sequence (green). C.

432 Fragments were used to assess extended sequence on both sides of the 10-base sequence.

433 Proximal site (blue), 14 bases (red), 16 bases (light blue), 10 bases (green), scram (orange), no 434 DNA (purple). Panels A-C used $3 \mu \mathrm{M}$ CopY to assess binding to each of the fragments. D. A 435 fragment containing 19 of the 21 bases in the repeat has comparable levels of binding to the 436 fully repeat. The following concentrations were used to establish the $\mathrm{K}_{\mathrm{d}}, 1000 \mathrm{nM}$ (blue), $500 \mathrm{nM}$ 437 (red), $250 \mathrm{nM}$ (light blue), $125 \mathrm{nM}$ (green), $62.5 \mathrm{nM}$ (orange), $15.6 \mathrm{nM}$ (purple) CopY. Data is 438 representative of three experimental replicates. 
440 Figure 7. Pneumococcal CopY binds to E. hirae DNA in accordance with the newly

441 proposed consensus cop operon operator. Affinity of CopY binding to various DNA

442 fragments was determined using the following concentrations of CopY $1000 \mathrm{nM}$ (blue), $500 \mathrm{nM}$

443 (red), $250 \mathrm{nM}$ (light blue), $125 \mathrm{nM}$ (green), $62.5 \mathrm{nM}$ (orange), $15.6 \mathrm{nM}$ (purple) (A-D). A. E. hirae

444 proximal site. B. E. hirae distal site C. 19-base fragment with a T to C mutation. D. 19-base

445 fragment with a $\mathrm{T}$ to A mutation. For each figure, data is representative of three experimental

446 replicates.

447

448 Figure 8. Chart representing the previous, newly proposed pneumococcal, and newly

449 proposed CopY/R protein family consensus cop operon operator. Bases that change from

450 the initial 10-base consensus operator are highlighted in red. 


\section{REFERENCES}

452

453

454

455

456

457

458

459

460

461

462

463

464

465

466

467

468

469

470

471

472

473

474

475

476

477

478

479

480

481

482

483

484

485

486

487

488

489

490

491

492

493

494

495

496

497

498

499

1. Irving H, Williams RJP. 1953. 637. The stability of transition-metal complexes. Journal of the Chemical Society (Resumed) doi:10.1039/JR9530003192:3192-3210.

2. Imlay JA. The mismetallation of enzymes during oxidative stress.

3. Braymer JJ, Giedroc DP. 2014. Recent developments in copper and zinc homeostasis in bacterial pathogens. Current opinion in chemical biology 19:59-66.

4. Salgado CD, Sepkowitz KA, John JF, Cantey JR, Attaway HH, Freeman KD, Sharpe PAM, Michels HT, Schmidt MG. 2013. Copper Surfaces Reduce the Rate of Healthcare-Acquired Infections in the Intensive Care Unit. Infection Control and Hospital Epidemiology 34:479-486.

5. Warnes SL, Keevil CW. 2016. Lack of Involvement of Fenton Chemistry in Death of Methicillin-Resistant and Methicillin-Sensitive Strains of Staphylococcus aureus and Destruction of Their Genomes on Wet or Dry Copper Alloy Surfaces. Appl Environ Microbiol 82:2132-2136.

6. Macomber L, Hausinger RP. 2011. Mechanisms of nickel toxicity in microorganisms. Metallomics 3:1153-1162.

7. Kumar V, Mishra RK, Kaur G, Dutta D. 2017. Cobalt and nickel impair DNA metabolism by the oxidative stress independent pathway. Metallomics 9:1596-1609.

8. Kehl-Fie TE, Skaar EP. 2010. Nutritional immunity beyond iron: a role for manganese and zinc. Curr Opin Chem Biol 14:218-224.

9. Hood MI, Skaar EP. 2012. Nutritional immunity: transition metals at the pathogen-host interface. Nat Rev Microbiol 10:525-537.

10. Macomber L, Imlay JA. 2009. The iron-sulfur clusters of dehydratases are primary intracellular targets of copper toxicity. Proc Natl Acad Sci U S A 106:8344-8349.

11. Johnson MD, Kehl-Fie TE, Rosch JW. 2015. Copper intoxication inhibits aerobic nucleotide synthesis in Streptococcus pneumoniae. Metallomics 7:786-794.

12. Djoko KY, Phan MD, Peters KM, Walker MJ, Schembri MA, McEwan AG. 2017. Interplay between tolerance mechanisms to copper and acid stress in Escherichia coli. Proc Natl Acad Sci U S A 114:6818-6823.

13. Djoko KY, McEwan AG. 2013. Antimicrobial action of copper is amplified via inhibition of heme biosynthesis. ACS Chem Biol 8:2217-2223.

14. Macomber L, Rensing C, Imlay JA. 2007. Intracellular copper does not catalyze the formation of oxidative DNA damage in Escherichia coli. J Bacteriol 189:1616-1626.

15. Miao X, He J, Zhang L, Zhao X, Ge R, He QY, Sun X. 2018. A Novel Iron Transporter SPD_1590 in Streptococcus pneumoniae Contributing to Bacterial Virulence Properties. Front Microbiol 9:1624.

16. Honsa ES, Johnson MD, Rosch JW. 2013. The roles of transition metals in the physiology and pathogenesis of. Frontiers in cellular and infection microbiology 3:92.

17. Shafeeq S, Yesilkaya H, Kloosterman TG, Narayanan G, Wandel M, Andrew PW, Kuipers OP, Morrissey JA. 2011. The cop operon is required for copper homeostasis and contributes to virulence in Streptococcus pneumoniae. Molecular microbiology 81:1255-1270.

18. Rosch JW, Sublett J, Gao G, Wang YD, Tuomanen El. 2008. Calcium efflux is essential for bacterial survival in the eukaryotic host. Molecular microbiology 70:435444.

19. Rosch JW, Gao G, Ridout G, Wang YD, Tuomanen El. 2009. Role of the manganese efflux system mntE for signalling and pathogenesis in Streptococcus pneumoniae. Molecular microbiology 72:12-25. 
500 20. Honsa ES, Johnson MDL, Rosch JW. 2013. The roles of transition metals in the

501

502

503

504

505

506

507

508

509

510

511

512

513

514

515

516

517

518

519

520

521

522

523

524

525

526

527

528

529

530

531

532

533

534

535

536

537

538

539

540

541

542

543

544

545

546

547

548

549

550

physiology and pathogenesis of Streptococcus pneumoniae. Frontiers in Cellular and Infection Microbiology 3.

21. Shafeeq S, Kuipers OP, Kloosterman TG. 2013. The role of zinc in the interplay between pathogenic streptococci and their hosts. Molecular microbiology 88:1047-1057.

22. Strausak D, Solioz M. 1997. CopY is a copper-inducible repressor of the Enterococcus hirae copper ATPases. The Journal of biological chemistry 272:8932-8936.

23. Smaldone GT, Helmann JD. 2007. CsoR regulates the copper efflux operon copZA in Bacillus subtilis. Microbiology 153:4123-4128.

24. Corbett D, Schuler S, Glenn S, Andrew PW, Cavet JS, Roberts IS. 2011. The combined actions of the copper-responsive repressor CsoR and copper-

metallochaperone CopZ modulate CopA-mediated copper efflux in the intracellular pathogen Listeria monocytogenes. Molecular microbiology 81:457-472.

25. Vollmecke C, Drees SL, Reimann J, Albers SV, Lubben M. 2012. The ATPases CopA and CopB both contribute to copper resistance of the thermoacidophilic archaeon Sulfolobus solfataricus. Microbiology 158:1622-1633.

26. Jacobs AD, Chang FMJ, Morrison L, Dilger JM, Wysocki VH, Clemmer DE, Giedroc DP. 2015. Resolution of Stepwise Cooperativities of Copper Binding by the Homotetrameric Copper-Sensitive Operon Repressor (CsoR): Impact on Structure and Stability. Angewandte Chemie-International Edition 54:12795-12799.

27. Johnson MD, Kehl-Fie TE, Klein R, Kelly J, Burnham C, Mann B, Rosch JW. 2015. Role of copper efflux in pneumococcal pathogenesis and resistance to macrophagemediated immune clearance. Infect Immun 83:1684-1694.

28. Singh K, Senadheera DB, Levesque CM, Cvitkovitch DG. 2015. The copYAZ Operon Functions in Copper Efflux, Biofilm Formation, Genetic Transformation, and Stress Tolerance in Streptococcus mutans. J Bacteriol 197:2545-2557.

29. Arguello JM, Gonzalez-Guerrero M, Raimunda D. 2011. Bacterial transition metal $\mathrm{P}(1 \mathrm{~B})-\mathrm{ATPases}$ : transport mechanism and roles in virulence. Biochemistry 50:99409949.

30. Hava DL, Camilli A. 2002. Large-scale identification of serotype 4 Streptococcus pneumoniae virulence factors. Molecular microbiology 45:1389-1406.

31. Stoyanov JV, Brown NL. 2003. The Escherichia coli copper-responsive copA promoter is activated by gold. The Journal of biological chemistry 278:1407-1410.

32. Neubert MJ, DahImann EA, Ambrose A, Johnson MDL. 2017. Copper Chaperone CupA and Zinc Control CopY Regulation of the Pneumococcal cop Operon. Msphere 2.

33. Glauninger $H$, Zhang Y, Higgins KA, Jacobs AD, Martin JE, Fu Y, Coyne Rd HJ, Bruce KE, Maroney MJ, Clemmer DE, Capdevila DA, Giedroc DP. 2018. Metaldependent allosteric activation and inhibition on the same molecular scaffold: the copper sensor CopY from Streptococcus pneumoniae. Chem Sci 9:105-118.

34. Liu T, Ramesh A, Ma Z, Ward SK, Zhang LM, George GN, Talaat AM, Sacchettini JC, Giedroc DP. 2007. CsoR is a novel Mycobacterium tuberculosis copper-sensing transcriptional regulator. Nature Chemical Biology 3:60-68.

35. Fu Y, Tsui HC, Bruce KE, Sham LT, Higgins KA, Lisher JP, Kazmierczak KM, Maroney MJ, Dann CE, 3rd, Winkler ME, Giedroc DP. 2013. A new structural paradigm in copper resistance in Streptococcus pneumoniae. Nat Chem Biol 9:177-183.

36. Fu Y, Bruce KE, Wu HW, Giedroc DP. 2016. The S2 Cu(I) site in CupA from Streptococcus pneumoniae is required for cellular copper resistance. Metallomics 8:6170.

37. Changela A, Chen K, Xue Y, Holschen J, Outten CE, O'Halloran TV, Mondragon A. 2003. Molecular basis of metal-ion selectivity and zeptomolar sensitivity by CueR.

Science 301:1383-1387. 
38. Safo MK, Zhao QX, Ko TP, Musayev FN, Robinson H, Scarsdale N, Wang AHJ, Archer GL. 2005. Crystal structures of the Blal repressor from Staphylococcus aureus and its complex with DNA: Insights into transcriptional regulation of the bla and mec operons. Journal of Bacteriology 187:1833-1844.

39. Arede P, Oliveira DC. 2013. Proteolysis of mecA repressor is essential for expression of methicillin resistance by Staphylococcus aureus. Antimicrob Agents Chemother 57:2001-2002.

40. Altschul SF, Gish W, Miller W, Myers EW, Lipman DJ. 1990. Basic local alignment search tool. J Mol Biol 215:403-410.

41. Stols L, Gu MY, Dieckman L, Raffen R, Collart FR, Donnelly MI. 2002. A new vector for high-throughput, ligation-independent cloning encoding a tobacco etch virus protease cleavage site. Protein Expression and Purification 25:8-15.

42. Portmann R, Magnani D, Stoyanov JV, Schmechel A, Multhaup G, Solioz M. 2004. Interaction kinetics of the copper-responsive CopY repressor with the cop promoter of Enterococcus hirae. J Biol Inorg Chem 9:396-402.

43. Collins TC, Dameron CT. 2012. Dissecting the dimerization motif of Enterococcus hirae's Zn(II)CopY. Journal of Biological Inorganic Chemistry 17:1063-1070.

44. Gupta RS, Lo B, Son J. 2018. Phylogenomics and Comparative Genomic Studies Robustly Support Division of the Genus Mycobacterium into an Emended Genus Mycobacterium and Four Novel Genera. Front Microbiol 9:67.

45. Bailey TL, Johnson J, Grant CE, Noble WS. 2015. The MEME Suite. Nucleic Acids Res 43:W39-49.

46. Bailey TL, Boden M, Buske FA, Frith M, Grant CE, Clementi L, Ren J, Li WW, Noble WS. 2009. MEME SUITE: tools for motif discovery and searching. Nucleic Acids Res 37:W202-208.

47. Bailey TL, Elkan C. 1994. Fitting a mixture model by expectation maximization to discover motifs in biopolymers. Proc Int Conf Intell Syst Mol Biol 2:28-36.

48. Magnani D, Barre O, Gerber SD, Solioz M. 2008. Characterization of the CopR regulon of Lactococcus lactis IL1403. J Bacteriol 190:536-545.

49. Mrazek J, Xie S. 2006. Pattern locator: a new tool for finding local sequence patterns in genomic DNA sequences. Bioinformatics 22:3099-3100.

50. Odermatt A, Solioz M. 1995. Two trans-acting metalloregulatory proteins controlling expression of the copper-ATPases of Enterococcus hirae. J Biol Chem 270:4349-4354.

51. Slager J, Aprianto R, Veening JW. 2018. Deep genome annotation of the opportunistic human pathogen Streptococcus pneumoniae D39. Nucleic Acids Res 46:9971-9989.

52. Gregory PD, Lewis RA, Curnock SP, Dyke KG. 1997. Studies of the repressor (Blal) of beta-lactamase synthesis in Staphylococcus aureus. Mol Microbiol 24:1025-1037.

53. van Opijnen T, Camilli A. 2012. A fine scale phenotype-genotype virulence map of a bacterial pathogen. Genome Res 22:2541-2551. 
bioRxiv preprint doi: https://doi.org/10.1101/676700; this version posted June 21,2019 . The copyright holder for this preprint (which was not certified by peer review) is the author/funder. All rights reserved. No reuse allowed without permission.

591 Table 1

\begin{tabular}{|c|c|c|}
\hline Construct & $\mathrm{K}_{\mathrm{d}}(\mathrm{nM} \mathrm{M})$ & $\mathbf{R}^{2}$ \\
\hline Two-Site & $28.1 \pm 0.2$ & 0.9474 \\
\hline Distal Site & $55.2 \pm 0.4$ & 0.9432 \\
\hline Proximal Site & $25.5 \pm 0.2$ & 0.9475 \\
\hline 16-base & $360 \pm 4$ & 0.9808 \\
\hline 19-base & $37.1 \pm 0.3$ & 0.9552 \\
\hline 19-base T to $C$ & $40.4 \pm 0.3$ & 0.9408 \\
\hline E. hirae (Proximal) & $164 \pm 2$ & 0.9269 \\
\hline
\end{tabular}

592 
bioRxiv preprint doi: https://doi.org/10.1101/676700; this version posted June 21, 2019. The copyright holder for this preprint (which was not certified by peer review) is the author/funder. All rights reserved. No reuse allowed without permission.

\section{Table 2}

\begin{tabular}{|c|c|c|c|c|}
\hline Organism & Closest Downstream Gene & Sequence & CopY/R Binding & Reference \\
\hline Lactococcus lactis & $y t j D 1$ & AAATAGTTTACAAGTGTAAATTTATTT & Yes & Magnani et al., 2008 \\
\hline & $y d i D$ & AAAATGTTTACATGTGTAAATTTTCAC & Yes & Magnani et al., 2008 \\
\hline & $\operatorname{cop} R$ & TTAGTGTTTACACGTGTAAACTTATCT & Yes & Magnani et al., 2008 \\
\hline & $\operatorname{cop} B$ & TGATAGTTTACAATTGTAAACTATATA & Yes & Magnani et al., 2008 \\
\hline & yahc & TTTTCGTTTACAATTGTAAACATAGAA & Yes & Magnani et al., 2008 \\
\hline & IctO & СТАTCATCTACAGATGTAAACTTTATA & Yes & Magnani et al., 2008 \\
\hline & $y t j D 2$ & GATAAGATTACATATGTAAACAATAAA & Yes & Magnani et al., 2008 \\
\hline & yfhF & TAAGTATATACATCTGTAAAACTGAAA & No & Magnani et al., 2008 \\
\hline & $y x d E$ & TTTGCTATTACAСТTGTATCACATAAA & No & Magnani et al., 2008 \\
\hline Streptococcuspneumoniae & SP_0090 1 & TGATTTAGGACATTTGTTTGATAGTGG & No & This Study \\
\hline & $S P \_00902$ & GAGTATACTAATAATGTAATCGTTATC & No & This Study \\
\hline & $S P \_0045$ & GGTGAACTAACAGATGTTTACGAAATT & No & This Study \\
\hline & SP_0530 & ATTTGAGGAACAAATGTACGTTTATAA & No & This Study \\
\hline & SP_1433 & GTAATTATAACAGATGTATAATAGAAA & No & This Study \\
\hline & SP_1863 & ATGAATAAAACAATTGTAACACTCATC & No & This Study \\
\hline & SP_2073 & AAGGCGGAAACATGTGTCAATGACTTG & No & This Study \\
\hline & $\operatorname{cop} Y$ (Proximal Site) & GTGTAATTGACAAATGTAGATTTTGGA & Yes & This Study \\
\hline & $\operatorname{cop} Y$ (Distal Site) & СTATAATT GACAAATGTAGATTTTAAG & Yes & This Study \\
\hline
\end{tabular}


bioRxiv preprint doi: https://doi.org/10.1101/676700; this version posted June 21,2019 . The copyright holder for this preprint (which was not certified by peer review) is the author/funder. All rights reserved. No reuse allowed without permission.

\section{Figure 1}

A.

TIGR4 COpY Operators

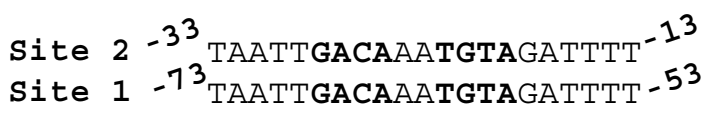

B.

E. hirae ATCC 9790 -66 AATTTTCGATTACAGTTGTAATCTAT--..-- - TATCGAAGTTAAGTTTACAAATGTAATCGATGGAGGTGAAAAACCA

S. pneumoniae TIGR4 -73

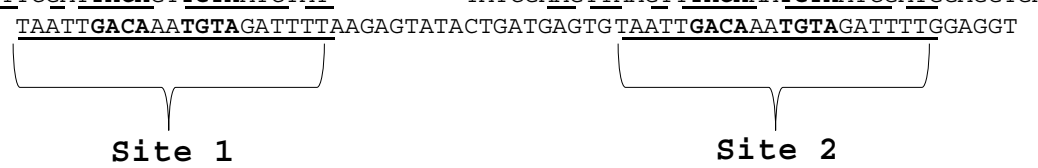

596

Distal

Proximal 


\section{Figure 2}

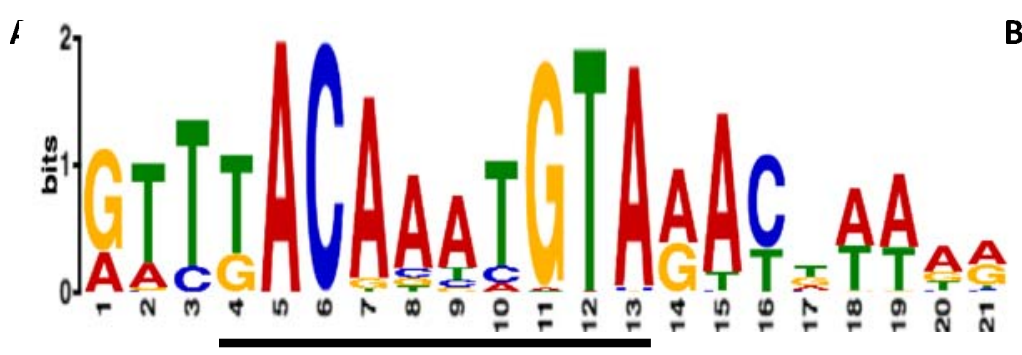

B. Unique DNA Sequences

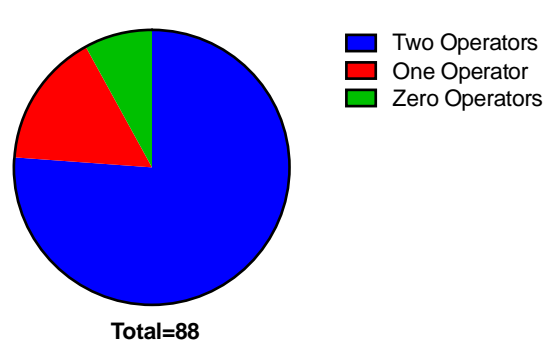

C. Genera with Two Consensus Operators

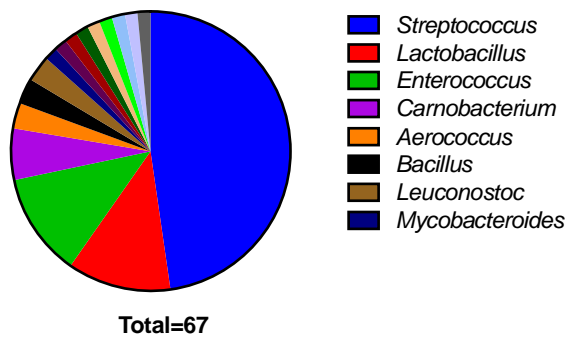

D. Genera with One Consensus Operator

$\square$ Chlamydia

- Escherichia

Dolosigranulum

$\square$ Fastidiosipila

$\square$ Granulicatella

$\square$ Jeotgalibaca

$\square$ Tissierellia

$\square$ Weissella

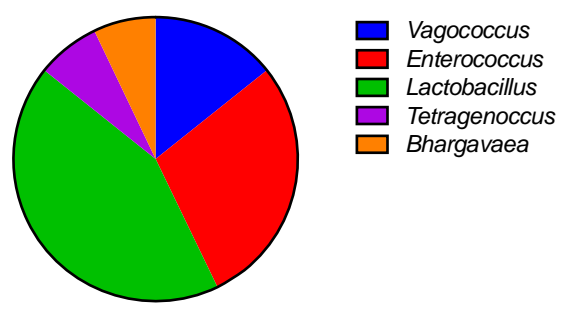

Total $=14$ 


\section{Figure 3}

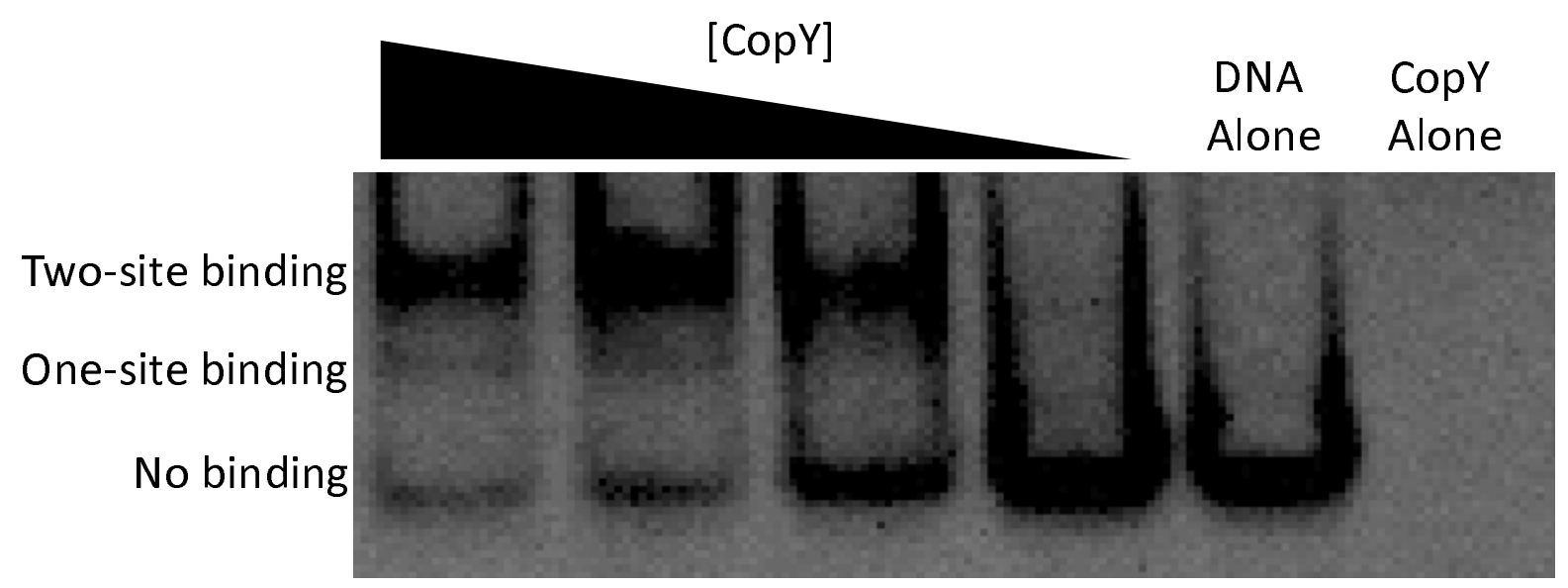

600 


\section{$601 \quad$ Figure 4}
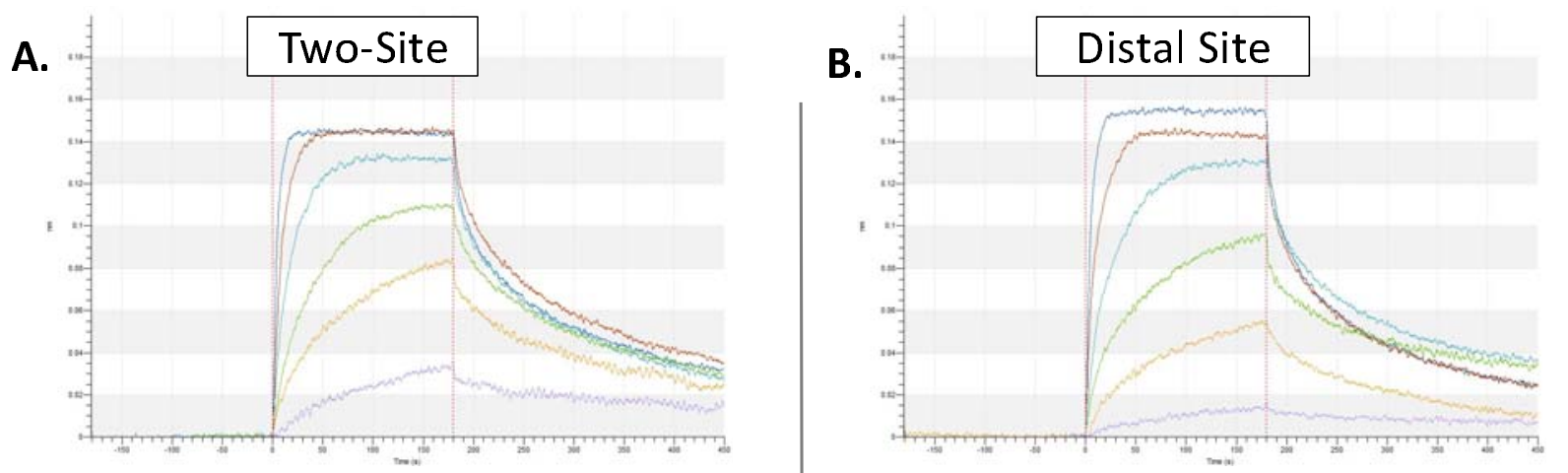

C.

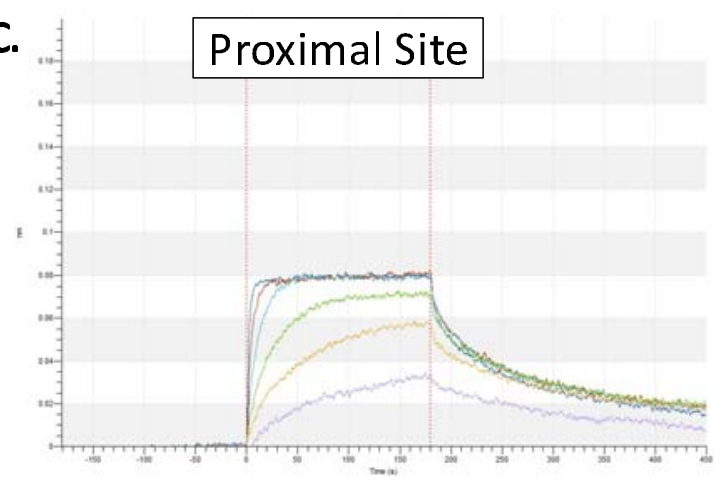

D.

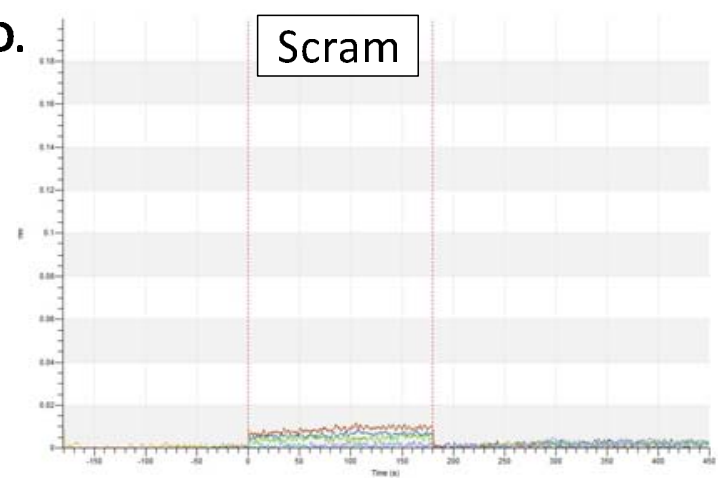


bioRxiv preprint doi: https://doi.org/10.1101/676700; this version posted June 21,2019 . The copyright holder for this preprint (which was not certified by peer review) is the author/funder. All rights reserved. No reuse allowed without permission.

\section{$603 \quad$ Figure 5}

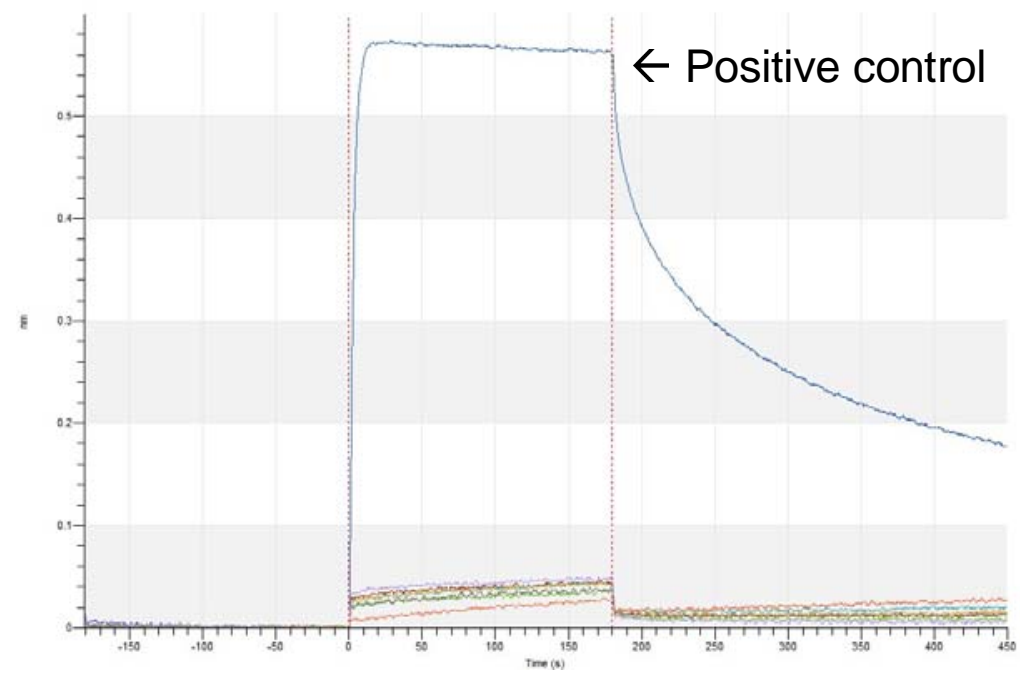

604 
605 Figure 6

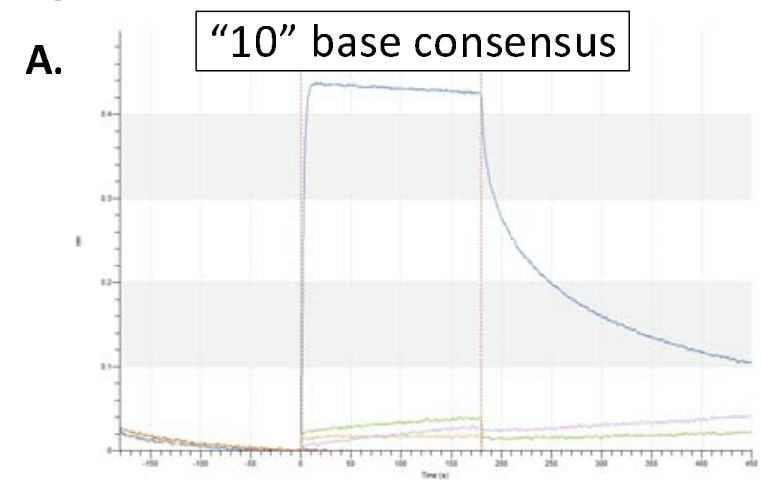

C. $10 \mathrm{bp} \mathrm{w/} \mathrm{up-} \mathrm{and} \mathrm{downstream}$

606

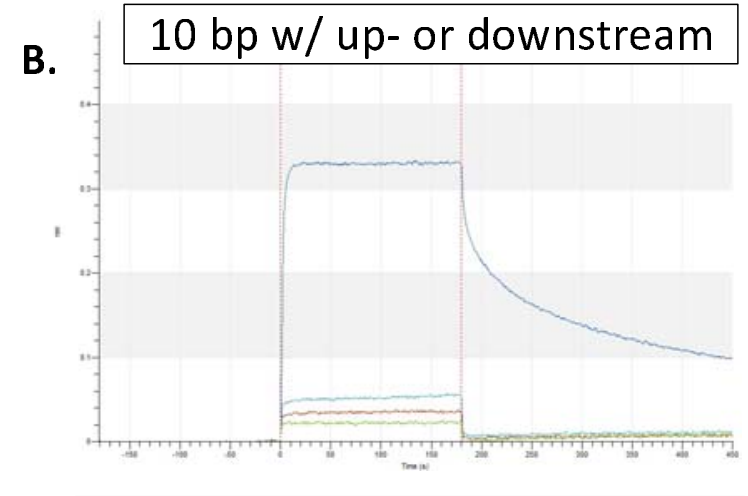

D.
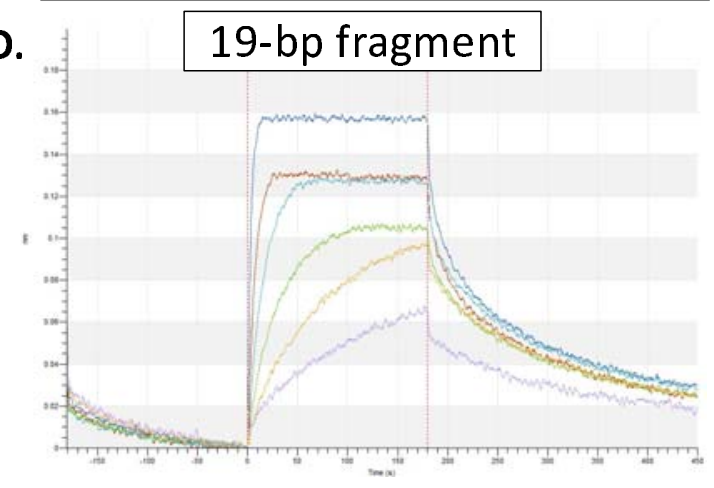
$607 \quad$ Figure 7

A.

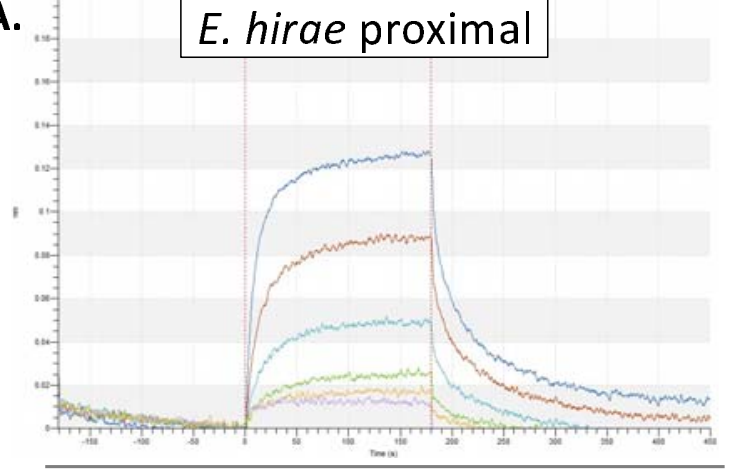

C.

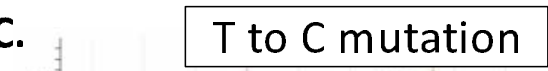

608
B.

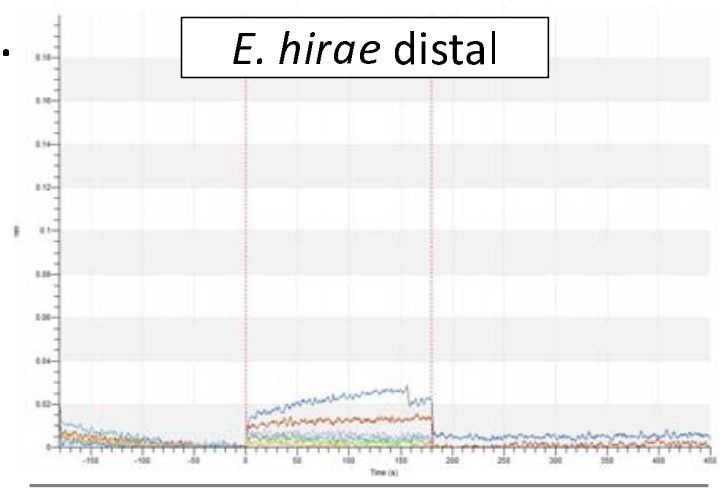

D.

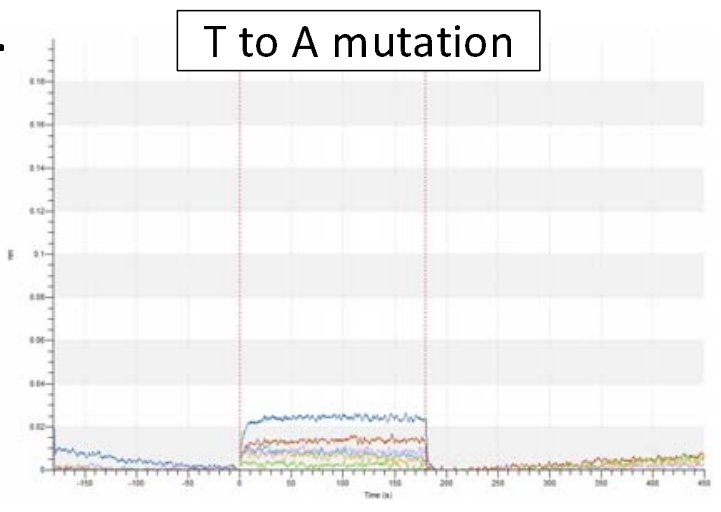


Figure 8

\begin{tabular}{|ll|}
\hline Previous Consensus & nnnKACAnnTGTAnnn \\
S. pneumoniae & RnYKACAAATGTARnY \\
New Total Consensus & RnYKACAnnYGTARnY \\
\hline
\end{tabular}

